\title{
Investigation of chemical characteristics and spatiotemporal quantitative changes of dust fall using GIS and RS technologies; a case study, Yazd city, central plateau of Iran
}

\author{
Hamid Reza Azimzadeh ${ }^{1}$, Reza Ali Fallahzadeh ${ }^{2}$, Mohammad Taghi Ghaneian $^{3 *}$, Seyed Ali Almodaresi ${ }^{4}$, Hadi \\ Eslami $^{2}$, Mahmoud Taghavi ${ }^{5}$
}

${ }^{1}$ Associate Professor, Department of Environmental Science, School of Natural Resources \& Desert Studies, Yazd University, Yazd, Iran ${ }^{2} \mathrm{PhD}$ Candidate, Environmental Science and Technology Research Center, Department of Environmental Health Engineering, Student Research Committee, Shahid Sadoughi University of Medical Sciences, Yazd, Iran

${ }^{3}$ Associate Professor, Environmental Science and Technology Research Center, Department of Environmental Health Engineering, Shahid Sadoughi University of Medical Sciences, Yazd, Iran

${ }^{4}$ Associate Professor, Department of GIS \& RS, Engineering College, Islamic Azad University, Yazd Branch, Yazd, Iran ${ }^{5} \mathrm{PhD}$ Candidate, Department of Environmental Health Engineering, Gonabad University of Medical Sciences, Gonabad, Iran

\begin{abstract}
Background: The phenomenon of dust is a serious environmental problem in dry and semi dry regions. It has a destructive effect for the residents of such regions. Over two-thirds of Iran is in areas of dry and semi-dry climate conditions.

Methods: In this research, dust fall measurements were taken in 41 stations across Yazd city using a marble dust collector (MDCO) located in different parts of the city. Next, the chemical characteristics of dust were determined using the XRF method. Finally, levels of dust fall across the 4 seasons of the year and status of the constituent elements of dust were determined through ArcGIS software and the Kriging technique. The Raster calculator function was used to make determinations of the effects of dust fall at each of the stations over the course of the year. Remote sensing system, along with maps taken from Landsat and the band combination technique were processed using ENVI software to extract vegetation density and building density maps of the studied region.

Results: Results showed that spring had the highest level of dust fall with a value of $200 \mathrm{~g} / \mathrm{cm}^{2}$. In total, in $109 \mathrm{~km}^{2}$ of the studied region had average dust fall of $110 \mathrm{~g} / \mathrm{m}^{2}$ that contributed to 12057 tons of dust over Yazd city in 2015. The constituent elements of the dust fall according to decreasing amounts were as follows: $\mathrm{Si}>\mathrm{Ca}>\mathrm{Al}>\mathrm{C}>\mathrm{Mg}>\mathrm{Fe}>\mathrm{K}>\mathrm{Na}>\mathrm{S}>\mathrm{Ti}>\mathrm{Cl}>\mathrm{P}>\mathrm{Mn}>\mathrm{Sr}>\mathrm{Zn}$.

Conclusion: These results indicate accuracy of the Kriging technique for application in dust zoning. The factors of vegetation and green space were determined as effective on adsorbing dust. Increased building density and height of buildings also contributed to development of dust fall.

Keywords: ArcGIS, ENVI, Remote sensing, Air pollution, Dust fall, Zoning

Citation: Azimzadeh HR, Fallahzadeh RA, Ghaneian MT, Almodaresi SA, Eslami H, Taghavi M. Investigation of chemical characteristics and spatiotemporal quantitative changes of dust fall using GIS and RS technologies; a case study, Yazd city, central plateau of Iran. Environmental Health Engineering and Management Journal 2017; 4(1): 45-53. doi: 10.15171/EHEM.2017.07.
\end{abstract}

\section{Article History:}

Received: 11 September 2016 Accepted: 19 November 2016 ePublished: 7 January 2017

\section{Introduction}

The detrimental effect of air pollution on human health was first identified in the 20th century. In 1930, sulfur dioxide emitted from a factory was mixed with a dense smog over the Meuse Valley in Belgium, where for three days, it caused acute pneumonic symptoms in thousands of people in the region. As a result of the incident, 60 people died from lung diseases (1). In December 1952, dense smog containing sulfur dioxide and smoke particulates spread throughout the entire city of London, causing the death of over 3000 people (2). At that time, the lethal potential of air pollution had been recognized but the relationship between air pollution and health was not well understood. Nowadays, due to the impact of air pollution on the incidence of disease in a specific population level, many physicians have properly understanding the relationship between air pollution and health (3).

In 1970, the Clean Air Act (CAA) was the first attempt to determine standard levels for emissions of air pollutants. Indeed, CAA defined the National Ambient Air Quality 
Standards (NAAQS). This standard stated declared standard limits for levels of the main 6 air pollutants. These pollutants included carbon monoxide, lead, nitrogen dioxide, ozone, sulfur dioxide, and particulate matters (PM) (4). PM is a mixture of small particles and tiny drops of liquid composed of acids, organic chemicals, metals, and soil or dust particles (5). PM can be from natural or artificial sources. Natural sources include volcanoes, fires, sand storms, and aerosolized sea salt (3). The World Health Organization (WHO) estimated that 500000 people die prematurely each year as a result of exposure to air-borne particulate matter in free air. The WHO has also estimated annual costs for the health sector caused by air pollution in Austria, France, and Switzerland at around 30 billion pounds, and that it accounts for $6 \%$ of all deaths (6). Various studies have considered the effects of these particles on health. Research confirms adverse effects of particles on cardiovascular functions $(7,8)$; the respiratory system (9-12) and even cerebrovascular problems $(13,14)$.

Today, 2 methods are used to measure dust fall: theoretical calculations and experimental measurement. In the experimental method, dust collectors and samplers are used to collect dust vertically and horizontally (15). In a study by Goossens and Offer in 2000 on horizontal and vertical sampling, results determined that the marble dust collector (MDCO) was the most efficient for collecting dust fall particles (16). MDCO was designed in 1975 and is a common and standard method for collecting dust (15). The mentioned device consists of a plastic container plus 1 or 2 rows of glass globes, which can be installed either on the ground or connected to a vertical pod. Various containing methods can be used, although circular containers are considered better than their rectangular counterparts, as they are more affected by wind direction. Standard glass globes have a diameter of $1.6 \mathrm{~cm}$. Glass globes are advantageous because they prevent dust from scattering out of the container in certain weather conditions such as strong winds or rain showers. It can be attributed to the roughness of the glass globes (17). Use of polyethylene Petri dishes as a passive sampler has been used as a standard method in several studies (18).

Geostatistics is widely used to determine variation and spatial distribution of pollutants (19). ArcGIS is powerful software for environmental modeling and geostatistical studies (20). GIS has been used in modeling and evaluation of pollutants including water (21-23), soil (24), and air (25, 26). In the majority of these studies, interpolation by the Kriging method has been introduced as the best and most accurate interpolation and preparation of curves to show levels of pollutants $(27,28)$. It is a geostatistical method that applies spatial variance, position, and distribution of samples (29). Kriging is an estimator that considers values of a variable in unsampled points as a linear combination of the values of that variable in relation to its surrounding points, as Relation 1, which gives a weight to every sample for estimating unknown points (30).

Relation 1:
$Z^{\circ}(X)=\sum_{i=1}^{n} \lambda_{i} z\left(x_{i}\right)$

In this relation, $Z^{\circ}$ is the estimated spatial variable, $z(x i)$ is the value of the spatial variable observed that $x i$ point, $\lambda i$ is the weight attributed to $x i$ sample, representing the significance of point $i$ in estimation.

Remote sensing is a method for gaining information about ground level from satellite images. Ground level latitude can often be determined using remote sensing and band combinations (31). Among the capabilities of remote sensing are determinations of vegetation (32) and building density (33). Vegetation and building density are specified using false color combination with selection of the bands intended for the development of RGB images in ENVI software (34). Urbanization has a great impact on the climate at micro and medium scale by converting vegetation into construction areas. It can be stated that the most apparent evidence of the human impact on climate at local and regional scale is that of the heat island method. Heat measurement can be used to reclaim ground level heat islands by recording the heat radiance levels emitted from the surface of a specified region (35).

The aim of this study was to investigate dust fall in terms of quantity and quality, zoning, and determination of influential factors. The first step in achieving this objective was to determine levels of dust fall and chemical characteristics. Then, using ArcGIS was used for zoning of the quality and quantity evaluations of dust fall. Eventually, by preparing vegetation and building maps using remote sensing, the effect of each of these issues was examined on quantity and quality evaluations of dust fall.

\section{Materials and methods}

This was a descriptive-analytical type study determining the chemical characteristics of dust fall over Yazd city. Dust fall zoning was done in ArcGIS, together with consideration of the status of dust distribution across different seasons in 2015. Subsequent evaluation was made by the Overlay method. This study investigated the status of vegetation, urbanization density, and its effect on quantity and quality of dust fall.

The studied region

The province of Yazd has a hot and dry desert climate. It is situated at the geographical location of $3^{\prime \prime} 22^{\prime} 54^{\circ} \mathrm{E}$ and $50^{\prime \prime} 53^{\prime} 31^{\circ} \mathrm{N}$ in the Yazd-Ardakan interior plain. The study area of Yazd city was located at $16^{\prime} 54^{\circ} \mathrm{E}$ to $26^{\prime} \mathrm{E}$ and $49^{\prime} 31^{\circ} \mathrm{N}$ until $57^{\prime} 31^{\circ} \mathrm{N}$ and covered an area of 110 $\mathrm{km}^{2}$, as shown in Figure 1. In the studied region, the predominant wind direction in the first 6 months of the year (spring and summer) was northwestern, while in the 4 months of November until February it was southeastern, and in March and October it was western. Within a 24hour period, there were 50 dusty days, and the greatest frequency occurred in the 60 days of summer, causing tangible and intangible damage for the people of Yazd province including Yazd city with a population of 526276 people. The average annual rainfall in Yazd was less than 
$60 \mathrm{~mm} /$ year.

The utilized MDCO sampler

The collector designed for this research consisted of a circular plastic container with a diameter of $22.5 \mathrm{~cm}$. Furthermore, inside the container there were three rows of glass globe that had been poured with a diameter of 1.6 $\mathrm{cm}$ to prevent dust from escaping (15-17).

Selection of sampling stations

For proper distribution of these above-mentioned collectors across the city, the major and most populated neighborhoods of the city were selected as sampling stations and collectors were installed at these locations. As can be observed in Figure 1, sampling stations were located at suitable distribution across different parts of the city.

Sampling, analysis, and zoning

By the end of September (within a 3-month period), the trapped dust was carefully collected from the collectors and weighed. For this purpose, a balance with an accuracy of $0.01 \mathrm{~g}$ was used. Then, XRF analysis was done on the collected dust. Following determination of the constituent elements of the dust samples, zoning was performed using the Kriging method by ArcGIS 10.2.2 software. Furthermore, amounts of dust fall across the four seasons; spring, summer, fall, and winter were determined by a similar method, zoned by ArcGIS. Using the Raster calculator function, an overlay map was prepared to identify regions that were most affected by dust across all seasons of the year $(36,37)$. Remote sensing was used to determine the region's vegetation. For this purpose, Image Landsat Archive (L4-5 TM sensor) available at

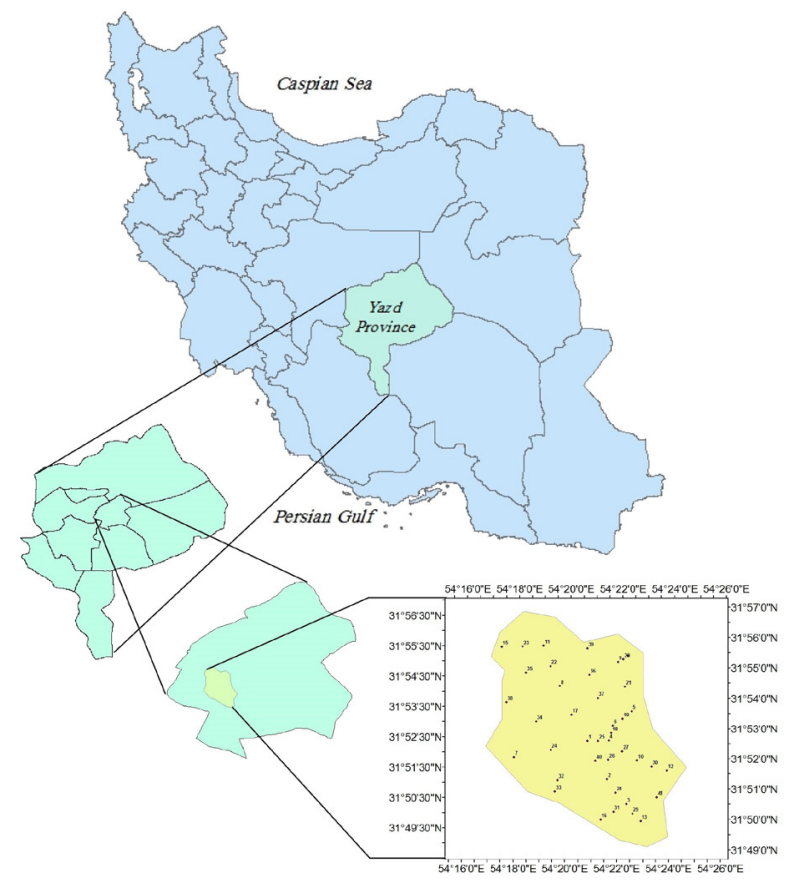

Figure 1. The characteristics of the studied region. http://earthexplorer.usgs.gov/ together with false color combination and development of RGB image with band combinations of 4 for R, e for $\mathrm{G}$, and 2 for B were used. Then, NDVI function in ENVI 4.7 software and eventually IsoData function along with unsupervised classification were employed (38-40). To determine building density in Yazd, Landsat heat infrared data of TM (Landsat), ETM+, and ASTER with respect to spatial power of 90,60, and 120 to extract the ground level temperature and make a more accurate study of urban heat islands that develop in urban regions $(41,42)$. Building density was determined by heat sensor using the Landsat archive (L8 OLI/TIRS) 8 sensor. To prepare maps, band combinations of 3 and 2 along with 11 heat bands were used to develop RGB images in ENVI software, showing building density in yellow.

\section{Results}

Measurement and zoning of dust fall

Seasonal measurement of dust fall in Yazd city in 2015 indicated that the mean dust fall in spring, summer, fall, and winter were 200, 119, 40.7, and $79.9 \mathrm{~g} / \mathrm{cm}^{2}$, respectively. Zoning of the status of dust fall across the different regions of Yazd city is shown in Figure 2. Overall, in 2015 in $109524581 \mathrm{~m}^{2}$ of the studied region, $110 \mathrm{~g} / \mathrm{m}^{2}$ dust fall has subsided on average, whereby we had 12047 tons of dust fall in Yazd city in total. Figure 3 demonstrates overlay points related to the 4 seasons of 2015, showing regions that were the most affected by dust fall.

Determination of chemical characteristics and zoning Following sampling of dust fall, its chemical characteristics were determined by the XRF method (Table 1). Values for the constituent elements $\mathrm{Al}, \mathrm{Ca}, \mathrm{C}, \mathrm{Fe}, \mathrm{K}, \mathrm{Cl}, \mathrm{Na}, \mathrm{Mn}$, $\mathrm{Mg}, \mathrm{Si}, \mathrm{S}, \mathrm{P}, \mathrm{Zn}$, Ti, Sr elements were specified. Based on these measurements, elements were presented in order of presence in dust fall, in terms of high to low value $\mathrm{Si}>\mathrm{Ca}$ $>\mathrm{Al}>\mathrm{C}>\mathrm{Mg}>\mathrm{Fe}>\mathrm{K}>\mathrm{Na}>\mathrm{S}>\mathrm{Ti}>\mathrm{Cl}>\mathrm{P}>\mathrm{Mn}>\mathrm{Sr}>\mathrm{Zn}$. Figure 4 represents zoning of each of these elements in the studied region.

Determining building density in the studied region Figure 5 illustrates building density of the studied region. This map was prepared to determine its effect on the quantity and quality of dust fall. In this image, regions with building construction are shown in yellow.

Determination of vegetation in the studied region

Figure 6 indicates a vegetation map extracted from Landsat satellite images using ENVI software. This image was prepared to investigate the effect of vegetation on quantity and quality of dust fall.

\section{Discussion}

Many studies have investigated dust fall in terms of quantity and quality as a pollutant. Tongqian and Bin used GIS to investigate dust fall as a pollutant (42). In the present study, dust fall was also measured across the four seasons of the year in 2015 in the city of Yazd. Results 

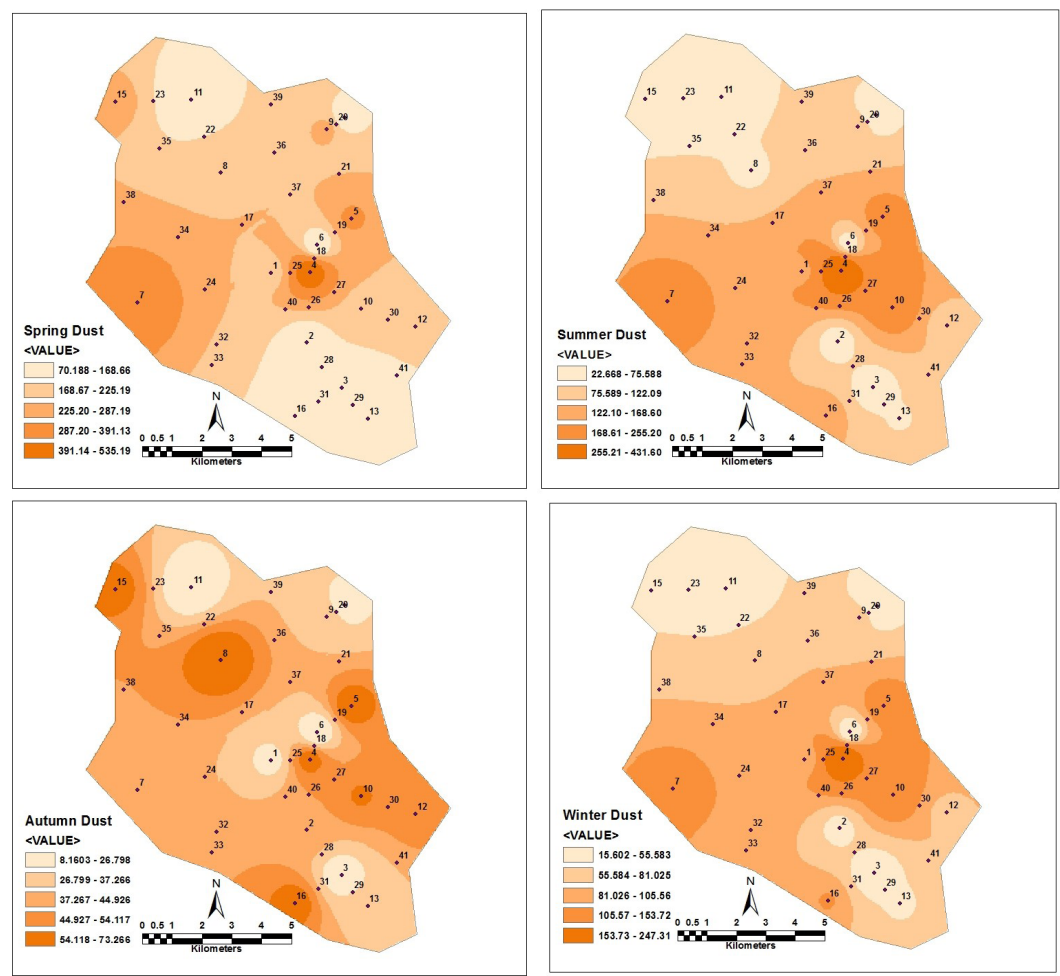

Figure 2. The dust fall in the studied region in 2015 by individual season $\left(\mathrm{g} / \mathrm{m}^{2}\right)$.

showed that spring and fall had higher and lower levels of dust fall with values of 200 and $40.7 \mathrm{~g} / \mathrm{m}^{2}$, respectively. The region was affected by a predominantly northwestern wind in spring. A study by Li et al, in the Tarim area in China investigated seasonal distribution of dust. Results showed that the highest level of dust in spring (43). The amount of dust fall was more than 12000 tons in 2015. Figure 3 shows a map overlay of dust fall covering the entire year of 2015. By corresponding this image with the image extracted for the buildings of Yazd from remote sensing, it was made clear that the highest level of dust fall had occurred in regions with higher building density. Reduced rainfall and increased wind erosion had also caused a high level of dust fall, and that factor should be further investigated.

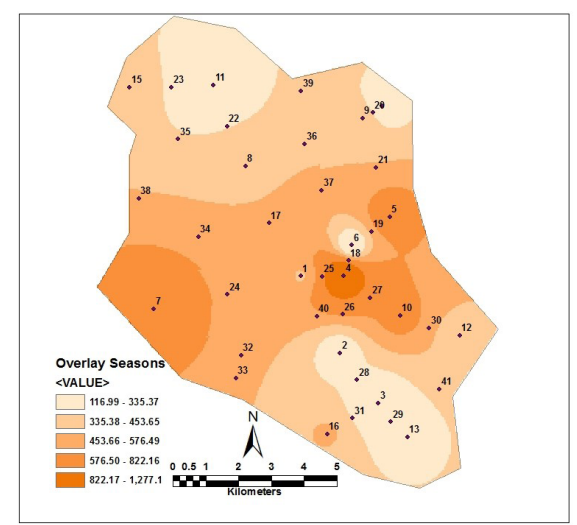

Figure 3. The map overlay of dust fall in Yazd city for all of four seasons in $2015\left(\mathrm{~g} / \mathrm{m}^{2}\right)$.
This study also examined the chemical quality of the dust fall (Figure 4). Based on results of analysis by the XRF method, Si had the most important role in the mixture of the analyzed dust, whereas $\mathrm{Zn}$ had the lowest value. The results of zoning of $\mathrm{Si}, \mathrm{Ca}, \mathrm{Al}, \mathrm{K}, \mathrm{Mg}$, and $\mathrm{Na}$ followed similar models, showing high values in regions with higher building density. In the study by Luo et al, the chemical characteristics of dust fall were examined in terms of presence of 40 trace elements. This study was performed in the Beijing region in 2013-2014. In this study, experiments were done on a total of 58 samples, followed by evaluation through multiple statistical methods and geographic information system (GIS). The results indicated that levels of pollutants increased according to increased urban traffic and density, such that the city center with the largest traffic load had higher levels of pollutants (44). A study on Hangzhou city in China by XU et al investigated the chemical characteristics of dust fall determined values for chromium, manganese, nickel, lead, zinc, cobalt, aluminum, iron, potassium, sodium, calcium and magnesium elements. Furthermore, the effect of human pollutants was examined on the elements quantified in the dust. Results showed a significant relationship between human-borne pollutants and elements present in the dust (45).

In Figure 5 less heat is observed in the region shown in the frame, in spite of it having high density. This region was located near sampling station 6 , which had a quantitatively lower level of dust. Investigation showed that in the mentioned region, the buildings were mainly old and built with clay (mud buildings), not to mention that most 
Table 1. The chemical characteristics of dust fall in Yazd city determined by the XRF method

\begin{tabular}{|c|c|c|c|c|c|c|c|c|c|c|c|c|c|c|c|}
\hline \multirow{2}{*}{$\begin{array}{l}\text { Sampling site } \\
\text { number }\end{array}$} & \multicolumn{15}{|c|}{ Type of chemical properties (w/w) } \\
\hline & Si & $\mathrm{Ca}$ & Al & C & $\mathrm{Mg}$ & $\mathrm{Fe}$ & $\mathbf{K}$ & $\mathrm{Na}$ & $\mathrm{S}$ & $\mathrm{Ti}$ & $\mathrm{Cl}$ & $\mathbf{P}$ & Mn & Sr & $\mathrm{Zn}$ \\
\hline 1 & 44.80 & 21.72 & 10.20 & 9.50 & 4.34 & 2.21 & 2.00 & 1.99 & 1.78 & 0.61 & 0.57 & 0.16 & 0.04 & 0.03 & 0.02 \\
\hline 2 & 43.70 & 21.57 & 10.40 & 8.80 & 4.36 & 0.34 & 2.08 & 2.23 & 2.91 & 0.56 & 0.82 & 0.17 & 0.05 & 0.02 & 0.00 \\
\hline 3 & 43.80 & 22.55 & 10.40 & 8.40 & 4.56 & 2.29 & 1.96 & 2.26 & 2.27 & 0.62 & 0.67 & 0.16 & 0.04 & 0.02 & 0.00 \\
\hline 4 & 44.50 & 22.30 & 10.20 & 9.30 & 4.21 & 2.22 & 2.04 & 1.97 & 1.82 & 0.55 & 0.57 & 0.17 & 0.05 & 0.03 & 0.01 \\
\hline 5 & 45.20 & 21.47 & 10.50 & 8.40 & 4.36 & 2.80 & 2.03 & 2.14 & 1.69 & 0.63 & 0.62 & 0.15 & 0.05 & 0.02 & 0.00 \\
\hline 6 & 43.20 & 21.38 & 10.40 & 8.30 & 4.36 & 2.23 & 2.02 & 2.32 & 4.19 & 0.57 & 0.83 & 0.17 & 0.04 & 0.01 & 0.00 \\
\hline 7 & 34.50 & 19.21 & 7.88 & 0.60 & 3.13 & 2.86 & 1.71 & 1.52 & 1.55 & 0.47 & 0.58 & 0.14 & 0.05 & 0.03 & 0.00 \\
\hline 8 & 32.80 & 18.49 & 7.40 & 8.70 & 2.99 & 1.97 & 1.62 & 1.47 & 1.90 & 0.47 & 0.61 & 0.12 & 0.04 & 0.01 & 0.00 \\
\hline 9 & 42.70 & 21.18 & 10.30 & 9.30 & 4.23 & 4.75 & 2.01 & 1.94 & 2.13 & 0.51 & 0.73 & 0.19 & 0.07 & 0.02 & 0.01 \\
\hline 10 & 45.70 & 22.16 & 10.20 & 8.20 & 4.14 & 2.21 & 1.99 & 2.17 & 1.80 & 0.58 & 0.66 & 0.16 & 0.05 & 0.05 & 0.00 \\
\hline 11 & 35.20 & 18.23 & 8.07 & 7.00 & 3.24 & 2.05 & 1.73 & 1.86 & 2.68 & 0.49 & 0.84 & 0.14 & 0.04 & 0.02 & 0.00 \\
\hline 12 & 41.30 & 22.79 & 10.80 & 9.60 & 4.55 & 3.36 & 2.31 & 2.07 & 1.67 & 0.51 & 0.87 & 0.18 & 0.05 & 0.03 & 0.00 \\
\hline 13 & 35.40 & 19.39 & 8.09 & 6.20 & 3.29 & 2.17 & 1.72 & 1.68 & 2.49 & 0.52 & 0.68 & 0.12 & 0.05 & 0.02 & 0.00 \\
\hline 14 & 43.40 & 22.42 & 10.10 & 9.10 & 4.39 & 2.23 & 2.01 & 2.47 & 2.20 & 0.56 & 1.03 & 0.21 & 0.04 & 0.02 & 0.00 \\
\hline 15 & 42.60 & 19.63 & 10.40 & 12.0 & 4.30 & 2.35 & 2.01 & 2.48 & 2.94 & 0.56 & 0.94 & 0.20 & 0.05 & 0.02 & 0.00 \\
\hline 16 & 34.00 & 19.00 & 8.07 & 6.00 & 3.27 & 2.15 & 1.70 & 1.67 & 2.50 & 0.52 & 0.68 & 0.13 & 0.04 & 0.02 & 0.00 \\
\hline 17 & 38.80 & 20.11 & 8.80 & 9.10 & 3.67 & 2.09 & 1.81 & 1.73 & 1.84 & 0.55 & 0.59 & 0.14 & 0.04 & 0.02 & 0.00 \\
\hline 18 & 43.85 & 21.84 & 10.30 & 8.80 & 4.29 & 2.23 & 2.03 & 2.15 & 3.01 & 0.56 & 0.70 & 0.17 & 0.05 & 0.03 & 0.01 \\
\hline 19 & 44.35 & 21.43 & 10.45 & 8.35 & 4.36 & 2.52 & 2.03 & 2.23 & 2.94 & 0.60 & 0.73 & 0.16 & 0.05 & 0.02 & 0.00 \\
\hline 20 & 43.05 & 21.80 & 10.20 & 9.20 & 4.31 & 3.49 & 2.01 & 2.21 & 2.17 & 0.54 & 0.65 & 0.20 & 0.05 & 0.02 & 0.01 \\
\hline 21 & 43.95 & 21.33 & 10.40 & 8.85 & 4.30 & 3.78 & 2.02 & 2.04 & 1.91 & 0.57 & 0.67 & 0.17 & 0.06 & 0.02 & 0.01 \\
\hline 22 & 34.00 & 18.36 & 9.24 & 7.85 & 3.12 & 2.01 & 1.68 & 1.67 & 2.29 & 0.48 & 0.72 & 0.13 & 0.04 & 0.01 & 0.00 \\
\hline 23 & 38.90 & 18.93 & 9.24 & 9.50 & 3.77 & 2.20 & 1.87 & 2.17 & 2.81 & 0.53 & 0.89 & 0.17 & 0.05 & 0.02 & 0.00 \\
\hline 24 & 39.65 & 20.47 & 9.04 & 9.05 & 3.74 & 2.54 & 1.86 & 1.76 & 1.67 & 0.54 & 0.58 & 0.15 & 0.05 & 0.03 & 0.00 \\
\hline 25 & 44.65 & 22.01 & 8.80 & 9.40 & 4.28 & 2.22 & 2.02 & 1.98 & 1.80 & 0.58 & 0.57 & 0.17 & 0.05 & 0.03 & 0.02 \\
\hline 26 & 44.10 & 21.94 & 10.30 & 9.05 & 4.29 & 2.28 & 2.06 & 2.10 & 2.37 & 0.56 & 0.69 & 0.17 & 0.05 & 0.02 & 0.01 \\
\hline 27 & 45.10 & 22.23 & 10.20 & 8.75 & 4.18 & 2.22 & 2.15 & 2.07 & 1.81 & 0.57 & 0.62 & 0.17 & 0.05 & 0.04 & 0.01 \\
\hline 28 & 43.75 & 22.06 & 10.40 & 8.60 & 4.46 & 2.32 & 2.02 & 2.25 & 2.59 & 0.59 & 0.69 & 0.17 & 0.05 & 0.02 & 0.00 \\
\hline 29 & 39.60 & 20.97 & 9.25 & 7.30 & 3.93 & 2.23 & 1.84 & 1.97 & 2.38 & 0.57 & 0.68 & 0.14 & 0.04 & 0.02 & 0.00 \\
\hline 30 & 43.50 & 22.49 & 10.50 & 8.90 & 3.75 & 2.79 & 2.03 & 2.12 & 1.74 & 0.54 & 0.77 & 0.17 & 0.05 & 0.04 & 0.00 \\
\hline 31 & 38.90 & 20.78 & 13.27 & 10.20 & 5.55 & 3.30 & 2.68 & 2.80 & 3.64 & 0.83 & 1.01 & 0.21 & 0.07 & 0.02 & 0.00 \\
\hline 32 & 39.10 & 20.39 & 9.14 & 8.70 & 3.75 & 2.60 & 1.90 & 1.88 & 2.23 & 0.51 & 0.70 & 0.16 & 0.05 & 0.04 & 0.00 \\
\hline 33 & 43.25 & 19.11 & 12.01 & 6.30 & 4.84 & 3.58 & 2.56 & 2.43 & 3.28 & 0.75 & 0.97 & 0.20 & 0.07 & 0.03 & 0.00 \\
\hline 34 & 33.65 & 18.85 & 9.04 & 8.65 & 3.06 & 2.42 & 1.67 & 1.50 & 1.73 & 0.47 & 0.60 & 0.13 & 0.04 & 0.02 & 0.00 \\
\hline 35 & 37.70 & 19.06 & 8.90 & 10.35 & 3.65 & 2.16 & 1.82 & 1.58 & 2.42 & 0.52 & 0.78 & 0.16 & 0.05 & 0.01 & 0.00 \\
\hline 36 & 37.75 & 19.84 & 8.85 & 9.00 & 3.61 & 3.36 & 1.82 & 1.71 & 2.02 & 0.49 & 0.67 & 0.16 & 0.05 & 0.02 & 0.01 \\
\hline 37 & 39.00 & 19.98 & 8.95 & 8.55 & 3.68 & 2.39 & 1.83 & 1.81 & 1.80 & 0.55 & 0.61 & 0.13 & 0.04 & 0.02 & 0.00 \\
\hline 38 & 38.55 & 19.42 & 9.14 & 10.30 & 3.72 & 2.61 & 1.86 & 2.00 & 2.25 & 0.51 & 0.76 & 0.17 & 0.05 & 0.02 & 0.00 \\
\hline 39 & 39.30 & 20.33 & 9.09 & 0.05 & 3.82 & 2.14 & 1.87 & 2.58 & 2.44 & 0.52 & 0.70 & 0.18 & 0.04 & 0.02 & 0.00 \\
\hline 40 & 44.25 & 21.65 & 10.30 & 9.15 & 4.36 & 2.28 & 2.04 & 2.11 & 2.35 & 0.59 & 0.70 & 0.17 & 0.04 & 0.02 & 0.01 \\
\hline 41 & 38.35 & 21.09 & 9.45 & 7.90 & 3.92 & 2.77 & 2.02 & 1.88 & 2.09 & 0.52 & 0.78 & 0.15 & 0.05 & 0.02 & 0.00 \\
\hline Max & 45.70 & 22.79 & 13.27 & 12.00 & 5.55 & 4.75 & 2.68 & 2.80 & 4.19 & 0.83 & 1.03 & 0.21 & 0.07 & 0.05 & 0.02 \\
\hline Min & 32.80 & 18.23 & 7.40 & 0.05 & 2.99 & 0.34 & 1.62 & 1.47 & 1.55 & 0.47 & 0.57 & 0.12 & 0.04 & 0.01 & 0.00 \\
\hline Average & 40.73 & 20.73 & 9.72 & 8.32 & 4.00 & 2.50 & 1.96 & 2.02 & 2.29 & 0.55 & 0.72 & 0.16 & 0.05 & 0.02 & 0.00 \\
\hline RMSE $^{\mathrm{a}}$ & 0.841 & 0.586 & 0.723 & 0.222 & 0.47 & 0.62 & 0.20 & 0.28 & 0.55 & 0.06 & 0.11 & 0.02 & 0.00 & 0.00 & 0.00 \\
\hline
\end{tabular}

a For Kriging interpolation in ArcGIS software.

buildings in the region were single floor. Therefore, it can be concluded that the material and height of buildings can influence development of the heat island phenomenon as well as the quantity of dust fall. Clay (mud) is suitable thermal insulation materials and produce low intensity of the heat island phenomenon. In buildings made of mud, dust falling value also declined. In a study by Alamdar et al, the amount of arsenic in dust fall over Pakistan, and its effect on health were evaluated. In this study, the effect of height on the amount of arsenic present in dust was also inspected. The results revealed that height had a direct and significant relationship with amount of arsenic present in dust, whereby an increase in height also showed an increase in the value of arsenic. Furthermore, tests for arsenic present in collected human nail samples showed a similar model for the degree of absorption of arsenic in these regions such that the source of arsenic can be attributed to arsenic in dust (46).

In this research, the status of vegetation was also explored; images were extracted by remote sensing. Vegetation 

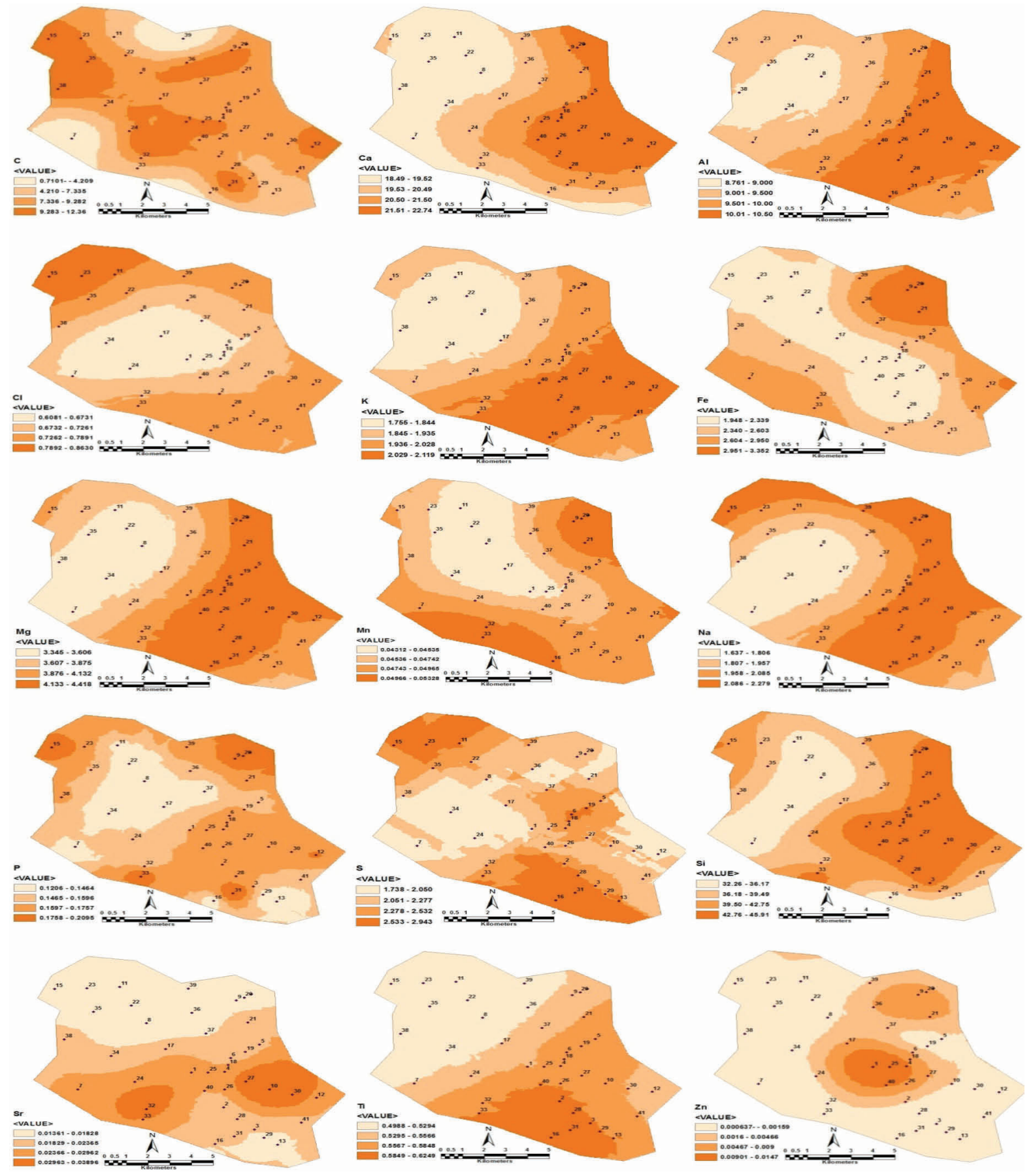

Figure 4. The zoning of the chemical characteristics of dust fall for Yazd in 2015.

and green space were determined as effective factors in adsorbing dust. Overall, decreased vegetation resulted in increased soil erosion, which was in turn one of the factors that increased dust fall. In a similar study done in China using GIS, on the effect of devastation of rangelands on dust development, it was found that the major reason for increased dust were human factors including rangeland devastation, over-cultivation, and abuse of water resources (47).

Information on dust zoning can be used for positioning studies, such as for health-sensitive centers that should be located with consideration of dust fall in the area. It should be noted that places such as kindergartens, nursing homes and schools, wherever possible, should not be exposed to high levels of dust fall. Research has shown that amounts of manganese and lead in dust fall were examined in a number of schools in Brazil over a 30-day period. Results of that study showed manganese and lead values at 1582 $\mu \mathrm{gMn} / \mathrm{m}^{2} / 30$ days and $43.2 \mu \mathrm{gPb} / \mathrm{m} 2 / 30$ days, respectively. Maps revealed that the factors of wind direction and construction site of schools influenced people's contact with dust containing manganese and lead (18).

In this study, the Kriging technique was used for interpolation. The last row in Table 1 shows the root 


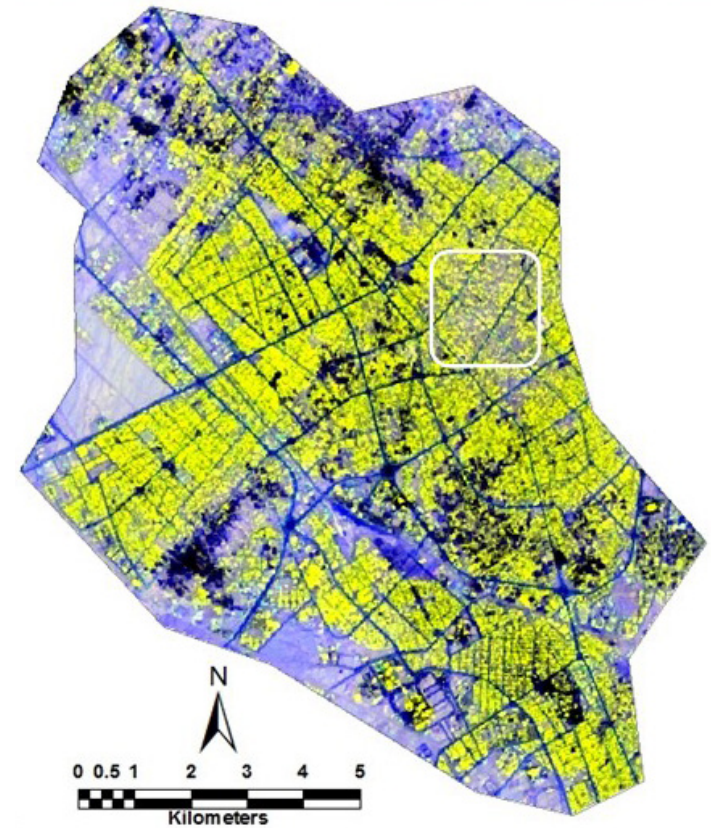

Figure 5. Building density map in Yazd in 2015.

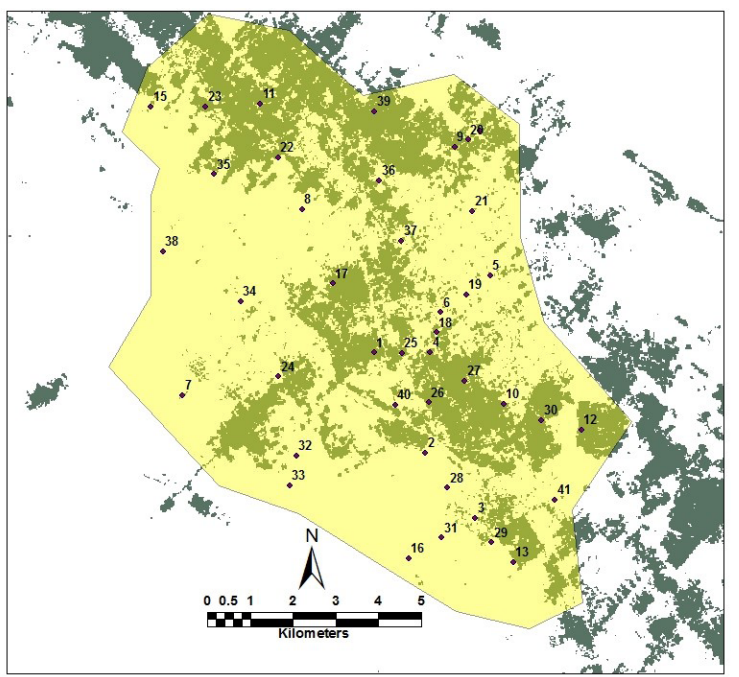

Figure 6. The vegetation map of the studied region.

mean square error (RMSE) value in zoning of each of the chemical parameters of dust fall. Low value of RMSE showed accuracy of the calculated interpolation. Based on the calculated RMSE, Kriging was determined as a suitable technique for interpolation of pollution related to dust fall in this study. So far, spatial interpolation techniques have been used in various studies considering environmental pollutants for zoning of pollutants and predicting their behavior across different sites. For example, Robinson et al studied the potential of different spatial interpolation techniques. Results showed that the Kriging method was the most accurate compared with other interpolation methods (48). Yasrebi et al also studied chemical parameters of soil with the aim of comparing IDW and Kriging techniques in predictions of spatial variability. The results of that study showed that the Kriging technique was more successful in predicting variability than IDW (49). Wong et al also proposed the Kriging technique to study air pollution (50).

\section{Conclusion}

Yazd province, with an ultra cold climate, is one of the provinces exposed to dust fall every year, such that in 2015, 12057 tons of dust fall encompassed Yazd city. The elements $\mathrm{Si}, \mathrm{Ca}$, and $\mathrm{Al}$ were determined as major constituents of the dust fall in Yazd, and the manner of their combination was different from region to region. The method of zoning is used for analyzing and evaluating dust fall across different points. The Kriging technique is a powerful interpolation technique for zoning dust fall and determination of the composition of its constituent elements. Remote sensing is also an effective and practical method to determine environmental complications affecting dust fall such as vegetation and building density. Examination of the density and height of buildings using remote sensing showed that these issues were involved in level of dust fall.

\section{Acknowledgements}

Our sincere thanks to Dr Ehrampoush the principal of public health college, Shahid Sadoughi university of medical sciences for permitting us to prepare this paper and Faculty members of department of environmental health engineering for their kind cooperation and encouragement. Also the authors would like to express their gratitude toward the Student Research Committee of Shahid Sadoughi University of Medical Sciences for funding this research.

\section{Ethical issues}

No ethical issues were relevant to this research.

\section{Competing interests}

Authors have no conflict of interests

\section{Authors' contributions}

HRA and MTG contributed to study conception and design; RAF and SAA contributed to analysis and interpretation of data and drafting of manuscript; HE and MTG contributed to critical revision; and MT contributed to acquisition of data.

\section{References}

1. Nemery B, Hoet PH, Nemmar A. The Meuse Valley fog of 1930: an air pollution disaster. Lancet 2001; 357(9257): 7048. doi: 10.1016/S0140-6736(00)04135-0.

2. Bell ML, Davis DL. Reassessment of the lethal London fog of 1952: novel indicators of acute and chronic consequences of acute exposure to air pollution. Environ Health Perspect 2001; 109(suppl 3): 389. doi: 10.2307/3434786.

3. Anderson JO, Thundiyil JG, Stolbach A. Clearing the air: a review of the effects of particulate matter air pollution on human health. J Med Toxicol 2012; 8(2): 166-75. doi: 10.1007/s13181-011-0203-1.

4. Bachmann J. Will the circle be unbroken: a history of the 
US National Ambient Air Quality Standards. J Air Waste Manag Assoc 2007; 57(6): 652-97. doi: 10.3155/10473289.57.10.1151.

5. Lippmann M, Frampton M, Schwartz J, Dockery D, Schlesinger R, Koutrakis P, et al. The US Environmental Protection Agency Particulate Matter Health Effects Research Centers Program: a midcourse report of status, progress, and plans. Environ Health Perspect 2003; 111(8): 1074-92.

6. Krzyzanowski M. WHO air quality guidelines for Europe. J Toxicol Environ Health A 2007; 71(1): 47-50. doi: $10.1080 / 15287390701557834$

7. Pope CA, Burnett RT, Thurston GD, Thun MJ, Calle EE, Krewski D, et al. Cardiovascular mortality and long-term exposure to particulate air pollution epidemiological evidence of general pathophysiological pathways of disease. Circulation 2004; 109(1): 71-7. doi: 10.1161/01. CIR.0000108927.80044.7F

8. Miller KA, Siscovick DS, Sheppard L, Shepherd K, Sullivan $\mathrm{JH}$, Anderson GL, et al. Long-term exposure to air pollution and incidence of cardiovascular events in women. $\mathrm{N}$ Engl J Med 2007; 356(5): 447-58. doi: 10.1056/NEJMoa054409.

9. McGowan JA, Hider RN, Chacko E, Town G. Particulate air pollution and hospital admissions in Christchurch, New Zealand. Aust N Z J Public Health 2002; 26(1): 23-9. doi: 10.1111/j.1467-842X.2002.tb00266.x.

10. Ostro B, Roth L, Malig B, Marty M. The effects of fine particle components on respiratory hospital admissions in children. Environ Health Perspect 2009; 117(3): 475-80. doi: 10.1289/ehp. 11848

11. Zeka A, Zanobetti A, Schwartz J. Short term effects of particulate matter on cause specific mortality: effects of lags and modification by city characteristics. Occup Environ Med 2005; 62(10): 718-25. doi: 10.1136/oem.2004.017012.

12. Zanobetti A, Schwartz J. The effect of fine and coarse particulate air pollution on mortality: a national analysis. Environ Health Perspect 2009; 117(6): 898-903. doi: 10.1289/ehp. 0800108 .

13. Wellenius GA, Schwartz J, Mittleman MA. Air pollution and hospital admissions for ischemic and hemorrhagic stroke among medicare beneficiaries. Stroke 2005; 36(12): 2549-53. doi: 10.1161/01.STR.0000189687.78760.47.

14. Villeneuve PJ, Chen L, Rowe BH, Coates F. Outdoor air pollution and emergency department visits for asthma among children and adults: a case-crossover study in northern Alberta, Canada. Environ Health 2007; 6: 40. doi: 10.1186/1476-069X-6-40.

15. Sow M, Goossens D, Rajot JL. Calibration of the MDCO dust collector and of four versions of the inverted frisbee dust deposition sampler. J Geomorph 2006; 82(3-4): 36075. doi: 10.1016/j.geomorph.2006.05.013.

16. Goossens D, Offer ZY. Wind tunnel and field calibration of six aeolian dust samplers. Atmos Environ 2000; 34(7): 1043-57. doi: 10.1016/S1352-2310(99)00376-3.

17. Huang Y, Jia Q. Coarse dust around mining areas: a study of available dust collectors and their efficiency [dissertation]. Lulea: Luleå University of Technology; 2008.

18. Menezes-Filho JA, Souza KO, Rodrigues JL, Santos NR, Bandeira Mde J, Koin NL, et al. Manganese and lead in dust fall accumulation in elementary schools near a ferromanganese alloy plant. Environ Res 2016; 148: 322-9. doi: $\quad 10.1016 /$ j.envres.2016.03.041.

19. Liu CW, Jang CS, Liao CM. Evaluation of arsenic contamination potential using indicator kriging in the YunLin aquifer (Taiwan). Sci Total Environ 2004; 321(1-3): 17388. doi: 10.1016/j.scitotenv.2003.09.002 .

20. Fedra K. GIS and environmental modeling. In: Goodchild MF, Parks BO, Steyaert LT, eds. Environmental Modeling with GIS. Oxford University Press; 1994. p. 35-50.

21. Merchant JW. GIS-based groundwater pollution hazard assessment: a critical review of the DRASTIC model. Photogramm Eng Remote Sensing 1994; 60(9): 1117-28.

22. Cattle JA, McBratney A, Minasny B. Kriging method evaluation for assessing the spatial distribution of urban soil lead contamination. J Environ Qual 2002; 31(5): 157688. doi: 10.2134/jeq2002.1576.

23. Fallahzadeh RA, Almodaresi SA, Dashti MM, Fattahi A, Sadeghnia M, Eslami H, et al. Zoning of nitrite and nitrate concentration in groundwater using geografic information system (GIS), case study: drinking water wells in Yazd City. Journal of Geoscience and Environment Protection 2016; 4(3): 91-6. doi: 10.4236/gep.2016.43008

24. Yan X, Shi W, Zhao W, Luo N. Mapping dustfall distribution in urban areas using remote sensing and ground spectral data. Sci Total Environ 2015; 506: 604-12. doi: 10.1016/j. scitotenv.2014.11.036.

25. Briggs DJ, Collins S, Elliott P, Fischer P, Kingham S, Lebret E, et al. Mapping urban air pollution using GIS: a regression-based approach. Int J Geogr Inf Sci 1997; 11(7): 699-718. doi: 10.1080/136588197242158

26. Siska PP, Hung IK. Assessment of Kriging Accuracy in the GIS Environment. 21st Annual ESRI International Conference; 2001; San Diego: Scholar Works; 2001.

27. Mueller TG, Pusuluri NB, Mathias KK, Cornelius PL, Barnhisel RI, Shearer SA. Map quality for ordinary kriging and inverse distance weighted interpolation. Soil Sci Am J 2004; 68(6): 2042-7. doi: 10.2136/sssaj2004.2042.

28. Kresic N. Hydrogeology and Groundwater Modeling. New York: CRC Press; 2006.

29. Johnston K, Ver Hoef JM, Krivoruchko K, Lucas N. Using ArcGIS Geostatistical Analyst. Redlands: ESRI; 2001.

30. Lillesand T, Kiefer RW, Chipman J. Remote Sensing and Image Interpretation. 7th ed. USA: John Wiley \& Sons; 2014.

31. Richardson AD, Anderson RS, Arain MA, Barr AG, Bohrer G, Chen G, et al. Terrestrial biosphere models need better representation of vegetation phenology: results from the North American Carbon Program Site Synthesis. Glob Chang Biol 2012; 18(2): 566-84. doi: 10.1111/j.13652486.2011.02562.x.

32. Pieraccini M, Luzi G, Mecatti D, Fratini M, Noferini L, Carissimi L, et al. Remote sensing of building structural displacements using a microwave interferometer with imaging capability. NDT E Int 2004; 37(7): 545-50. doi: 10.1016/j.ndteint.2004.02.004.

33. Jackson TJ, Chen D, Cosh M, Li F, Anderson M, Walthall $\mathrm{C}$, et al. Vegetation water content mapping using Landsat data derived normalized difference water index for corn and soybeans. Remote Sens Environ 2004; 92(4): 475-82. doi: 10.1016/j.rse.2003.10.021.

34. Balling RC, Brazel SW. High-resolution surface temperature patterns in a complex urban terrain. Photogramm Eng Remote Sensing 1988; 54(9): 1289-93.

35. Flindt MR, Rasmussen EK, Valdemarsen TB, Erichsen AC, Kaas H, Canal-Vergés P. Using a GIS-tool to evaluate potential eelgrass reestablishment in estuaries. Ecol Model. 
2016; 338: 122-34. doi: 10.1016/j.ecolmodel.2016.07.005.

36. Li X, Wang W, Li F, Deng X. GIS based map overlay method for comprehensive assessment of road environmental impact. Transportation Research Part D: Transport and Environment 1999; 4(3): 147-58. doi: 10.1016/s13619209(99)00002-4.

37. Carlson TN, Ripley DA. On the relation between NDVI, fractional vegetation cover, and leaf area index. Remote Sens Environ 1997; 62(3): 241-52. doi: 10.1016/S00344257(97)00104-1.

38. Tucker CJ, Pinzon JE, Brown ME, Slayback DA, Pak EW, Mahoney R, et al. An extended AVHRR 8-km NDVI dataset compatible with MODIS and SPOT vegetation NDVI data. Int J Remote Sensing 2005; 26(20): 4485-98. doi: $\quad 10.1080 / 01431160500168686$.

39. Anbazhagan S, Paramasivam CR. Statistical Correlation between Land Surface Temperature (LST) and Vegetation Index (NDVI) using Multi-Temporal Landsat TM Data. International Journal of Advanced Earth Science and Engineering 2016; 5(1): 333-46. doi: 10.3745/ JIPS.2005.1.1.102.

40. Amiri R, Weng Q, Alimohammadi A, Alavipanah SK. Spatial-temporal dynamics of land surface temperature in relation to fractional vegetation cover and land use/cover in the Tabriz urban area, Iran. Remote Sens Environ 2009; 113(12): 2606-17. doi: 10.1016/j.rse.2009.07.021.

41. Streutker DR. Satellite-measured growth of the urban heat island of Houston, Texas. Remote Sens Environ 2003; 85(3): 282-9. doi: 10.1016/S0034-4257(03)00007-5.

42. Tongqian Z, Bin H. Application of GIS on the space division and assessment or urban atmospheric dustfall pollution. Environ Pollut Control. 1999. http://en.cnki.com.cn/ Article_en/CJFDTOTAL-HJWR199902012.htm.

43. Li JC, Dong ZB, Wang XM, He SS. Seasonal Distribution and Causes of Dust Events in Tarim Basin,China. J Desert Res 2008; 28(1): 142-8.

44. Luo N, An L, Nara A, Yan X, Zhao W. GIS-based multielement source analysis of dustfall in Beijing: a study of 40 major and trace elements. Chemosphere 2016; 152: 123-31. doi: 10.1016/j.chemosphere.2016.02.099.

45. XU H, Lin FM, Bi XH, Jiao L, Feng YC, Hong SM, et al. Chemical characteristics of atmospheric dust fall and PM 10 in Hangzhou. China Environ Sci 2011; 31 (1): $1-7$.

46. Alamdar A, Eqani SA, Ali SW, Sohail M, Bhowmik AK, Cincinelli A, et al. Human Arsenic exposure via dust across the different ecological zones of Pakistan. Ecotoxicol Environ Saf 2016; 126: 219-27. doi: 10.1016/j. ecoenv.2015.12.044.

47. Wang Q, Otsubo K. A GIS based study on grassland degradation and increase of dust storm in China. Fundamental Issues Affecting Sustainability of the Mongolian Steppe. Ulaanbaatar: International Institute for the Study of Nomadic Civilizations (IISNC); 2002.

48. Robinson TP, Metternicht G. Testing the performance of spatial interpolation techniques for mapping soil properties. Comput Electron Agric 2006; 50(2): 97-108. doi: 10.1016/j. compag.2005.07.003.

49. Yasrebi J, Saffari M, Fathi H, Karimian N, Moazallahi M, Gazni R. Evaluation and comparison of ordinary kriging and inverse distance weighting methods for prediction of spatial variability of some soil chemical parameters. Res J Biol Sci 2009; 4(1): 93-102.

50. Wong DW, Yuan L, Perlin SA. Comparison of spatial interpolation methods for the estimation of air quality data. J Expo Sci Environ Epidemiol 2004; 14(5): 404-15. doi: 10.1038/sj.jea.7500338 